\title{
Respiratory Impedance and Bronchodilator Response in Healthy Italian Preschool Children
}

\author{
C. Calogero, ${ }^{1 \star}$ N. Parri, ${ }^{1}$ A. Baccini, ${ }^{1}$ B. Cuomo, ${ }^{2}$ M. Palumbo, ${ }^{2}$ E. Novembre, ${ }^{1}$ P. Morello, ${ }^{3}$ \\ C. Azzari, ${ }^{1}$ M. de Martino, ${ }^{1}$ P.D. Sly, ${ }^{4}$ and E. Lombardi ${ }^{1}$
}

\begin{abstract}
Summary. Objective: To define normal values for respiratory resistance $\left(R_{r s}\right)$ and reactance $\left(X_{r s}\right)$ and bronchodilator response (BDR) in a population of healthy Italian preschool children using a commercially available forced oscillation device. Methods: $R_{r s}$ and $X_{r s}$ were measured in kindergartens in Viterbo, Italy. Regression analysis was performed taking into account height, weight, age, gender, and reference equations calculated. The coefficient of repeatability (CR) between two tests performed $15 \mathrm{~min}$ apart was calculated in a subset of children. BDR was assessed by repeating the measurements $15 \mathrm{~min}$ after the administration of $200 \mu \mathrm{g}$ of inhaled salbutamol and calculated as an absolute change in $R_{r s}$ and $X_{r s}$ at $8 \mathrm{~Hz}$, as a percent change in baseline, and as a change in Z-score calculated from the reference equations. Results: Lung function was attempted in 175 healthy children and successful in 163 ( 81 male, median age 4.8, range 2.9-6.1 years). $R_{r s}$ and $X_{r s}$ at 6,8 , and $10 \mathrm{~Hz}$ were related to height but not other variables. The CR was $1.53 \mathrm{hPasL}^{-1}$ for $\mathrm{R}_{\mathrm{rs} 8}$ and $0.91 \mathrm{hPa} \mathrm{sL}^{-1}$ for $\mathrm{X}_{\mathrm{rs} 8}$. The 5 th percentile for absolute $\mathrm{R}_{\mathrm{rs} 8} \mathrm{BDR}$ was $-3.16 \mathrm{hPasL}^{-1}$, whereas the 95th percentile for absolute $\mathrm{X}_{\mathrm{rs} 8} \mathrm{BDR}$ was $2.25 \mathrm{hPa} \mathrm{sL}^{-1}$. These cut-off values corresponded to a change in the Z-score of -1.88 and 2.48, respectively. Conclusions: We have established reference equations for $R_{r s}$ and $X_{r s}$ in healthy Italian preschool children using forced oscillations. We recommend a change in Z-score of -1.88 for $R_{r s 8}$ and 2.48 for $X_{r s 8}$ as cut-off values for a positive BDR. Pediatr Pulmonol. 2010; 45:1086-1094. ๑ 2010 Wiley-Liss, Inc.
\end{abstract}

Key words: forced oscillations; children; reference values; bronchodilator.

Funding source: Associazione Solidarietà e Servizio NGO, Viterbo, Italy; Cassa di Risparmio di Viterbo, Italy.

\section{INTRODUCTION}

Lung function testing is important in evaluating patients with respiratory diseases. Adults and cooperative older children, usually from school age, can perform tests that require specific respiratory maneuvres, such as spirometry, which requires maximal inspiration and maximal forced expiration, to measure lung function. In preschool children such maneuvres are frequently not possible. Respiratory impedance $\left(\mathrm{Z}_{\mathrm{rs}}\right)$ can be measured with the forced oscillation technique (FOT). This is a useful tool in evaluating lung function in young children with limited ability to cooperate ${ }^{1}$ and older children. ${ }^{2-4}$ FOT has been shown to be applicable in the clinical evaluation of preschool children with cystic fibrosis ${ }^{5}$ as well as older children with cystic fibrosis during a respiratory tract exacerbation. ${ }^{6}$ Lung function measured with FOT has also been evaluated in children born prematurely with or without neonatal chronic lung disease. ${ }^{7-9}$ FOT has also been shown to be a valid tool in the assessment of bronchodilator response (BDR) in different populations of patients, especially asthmatic or wheezing children., ${ }^{4,10-14}$

Before FOT can be introduced into clinical practice as a routine test, appropriate reference values from healthy
${ }^{1}$ Section of Respiratory Medicine, Department of Paediatrics, University of Florence, “Anna Meyer" University Hospital for Children, Florence, Italy.

${ }^{2}$ Department of Paediatrics, "Belcolle" Hospital, Viterbo, Italy.

${ }^{3}$ Le Scotte University Hospital, Siena, Italy.

${ }^{4}$ Division of Clinical Sciences, Telethon Institute for Child Health Research and Centre for Child Health Research, University of Western Australia, Perth, Western Australia, Australia.

Partially presented at the American Thoracic Society meeting 2009 and the European Respiratory Society meetings 2008 and 2009.

*Correspondence to: C. Calogero, Section of Respiratory Medicine, Paediatric Allergy and Pulmonology Center, Department of Paediatrics, University of Florence, "Anna Meyer" University Hospital for Children, Viale Pieraccini 24, 50139 Florence, Italy. E-mail: c.calogero@meyer.it

Received 14 October 2009; Revised 20 May 2010; Accepted 22 May 2010.

DOI 10.1002/ppul.21292

Published online 29 July 2010 in Wiley Online Library

(wileyonlinelibrary.com). 
populations are needed. Although, a number of data sets from children have been published these are likely to be specific to the equipment used and to the study population. Other reference data sets from large samples of children have been previously published using the pseudorandom noise as the forcing function. ${ }^{2,15-18}$ Hall et al. ${ }^{18}$ have previously reported $\mathrm{Z}_{\mathrm{rs}}$ reference values in a population of Australian preschoolers using a commercially available FOT device that uses a pseudo-random noise as the forcing function. The Australian equation was compared to other equations previously published. ${ }^{18}$ To date, no assessment of whether these data are applicable to other populations has been published.

For the clinical application of the technique, knowing the repeatability of the test and the BDR in healthy subjects is also necessary. The between-measurement coefficient of repeatability (CR, i.e., twice the standard deviation of the difference between two measurements) for FOT has been reported in healthy children to be between 1.1 and $2.6 \mathrm{hPa} \mathrm{s} \mathrm{L}^{-1}$ for respiratory resistance $\left(\mathrm{R}_{\mathrm{rs}}\right)$ and between 1.2 and $1.7 \mathrm{hPas} \mathrm{L}{ }^{-1}$ for respiratory reactance $\left(\mathrm{X}_{\mathrm{rs}}\right){ }^{18-20}$ Thamrin et al. ${ }^{10}$ have shown BDR calculated as a percent change with respect to baseline of $-37 \%$ for $\mathrm{R}_{\mathrm{rs} 8}$ and $67 \%$ for $\mathrm{X}_{\mathrm{rs} 8}$ in healthy Australian children. Oostveen et al. ${ }^{14}$ have reported a decrease in resistance on average of $22 \%$ in wheezing children. In the present study, we measured lung function using FOT in 163 preschool aged Italian children to produce reference equations for $\mathrm{R}_{\mathrm{rs}}$ and $\mathrm{X}_{\mathrm{rs}}$ and to compare these with the Australian data. We also aimed to evaluate the repeatability of the test and to determine appropriate methods for assessing response to inhaled bronchodilator.

\section{MATERIALS AND METHODS}

\section{Study Subjects}

Children attending kindergartens in Viterbo, Italy were approached. Parents were sent a consent form and questionnaire by the education authorities and asked to return these to the child's kindergarten. The Ethics Committee of the Local Health Authority in Viterbo approved the study and written consent was obtained from the parents.

\section{Respiratory History}

Respiratory history was assessed using a standardized questionnaire (ISAAC modified). ${ }^{21}$ Subjects born at $<36$ weeks of gestational age or who had received oxygen after birth for more than 30 days were excluded. Subjects were defined as healthy, and thus included into the analysis, if they had never had a doctor diagnosis of asthma and had no more than three episodes of wheezing ever, with no episodes of wheezing during the previous 12 months. A personal history of atopy was defined as positive if the child had ever had allergic rhinitis and/or eczema. Also, parental history of atopy was considered to be positive if the parents had ever had allergic rhinitis or eczema or asthma and children were considered to be exposed to environmental tobacco smoke (ETS) if any family member smoked. All subjects were free of respiratory symptoms and signs at the time of testing.

\section{Lung Function Assessment}

Subjects underwent FOT measurements in the kindergartens in Viterbo. $\mathrm{R}_{\mathrm{rs}}$ and $\mathrm{X}_{\mathrm{rs}}$ were measured according to American Thoracic Society/European Respiratory Society (ATS/ERS) recommendations, ${ }^{1}$ using a commercial device (I2M; Chess Medical, Belgium, marketed by Cosmed, Rome, Italy), which uses a pseudo-random noise signal between 4 and $48 \mathrm{~Hz}$. The device was calibrated every day before the testing using a calibration device of known impedance. The impedance of the mouthpiece and bacterial filter (Cosmed, Italy) was measured and subtracted by the equipment software automatically. During the test subjects sat in an upright position with a neutral position of the head and were connected to the oscillation device by the mouthpiece incorporating a bacterial filter. They wore a nose clip and they were instructed to breathe normally at tidal volume. The cheeks and the floor of the mouth of the subject were supported during all measurements by one of the investigators. Measurements were excluded if a sudden drift on the volume tracing (suggesting an incomplete seal around the mouth) or a reduction/interruption of the flow oscillations (suggesting movement of the mouth or tongue, swallowing, talking, or glottal closure) were detected by visual control on the screen. ${ }^{1}$ The validity of the measurements at individual frequencies was assessed automatically by the software using the coherence function, which describes the statistical relationship between the input and output signals. A coherence function $\geq 0.95$ is taken as an acceptable limit for $\mathrm{Z}_{\mathrm{rs}}$ measurements. ${ }^{1}$ Individual frequencies that had a coherence function of $<0.95$ were excluded and the entire measurement was discarded if three or more individual frequencies were unacceptable. Between three and five data epochs lasting 8 sec each were recorded to obtain at least three acceptable measurements. ${ }^{1} \mathrm{R}_{\mathrm{rs}}$ and $\mathrm{X}_{\mathrm{rs}}$ were calculated for each frequency and the mean of the obtained measurements reported for each child at the frequencies of 6,8 , and $10 \mathrm{~Hz}$.

The short-term repeatability of the test was investigated in a subset of preschoolers. For this purpose, two sets of measurements were taken $15 \mathrm{~min}$ apart.

$\mathrm{BDR}$ was assessed by measuring again $\mathrm{Z}_{\mathrm{rs}} 15 \mathrm{~min}$ after the administration of $200 \mu \mathrm{g}$ of inhaled salbutamol administered at tidal breathing via MDI with a spacer (AeroChamber Plus, Trudell Medical International, London, ON, Canada). 


\section{Statistical Analysis}

Data are reported as mean and standard deviation (SD) or median and range, according to the distribution of the variable. Individual within-test variations for $\mathrm{Z}_{\mathrm{rs}}$ variables are expressed as coefficients of variation $(\mathrm{CV})$, calculated as: $\mathrm{CV}=(\mathrm{SD} /$ mean $) \times 100$, where $\mathrm{SD}$ is the standard deviation and the mean is the mean of all technically acceptable measurements. The coefficient of repeatability (CR) for two repeated sets of measurements was calculated as absolute value $(2 \times \mathrm{SD}$ of the difference between the repeated measurements) and as relative value $(2 \times \mathrm{SD}$ of the difference between repeated measurements as a percentage of the mean of the two measurements).

Stepwise multiple regression analysis was performed to take into account height, weight, age, and gender and potential effects of personal and parental history of atopy, and ETS exposure. Regression equations and the residual standard deviation (RSD) were determined for $\mathrm{R}_{\mathrm{rs}}$ and $\mathrm{X}_{\mathrm{rs}}$ at the frequencies of 6,8 , and $10 \mathrm{~Hz}$. BDR was assessed using three indices: absolute change in $\mathrm{R}_{\mathrm{rs} 8}$ and $\mathrm{X}_{\mathrm{rs} 8}$; percent change in $R_{r s 8}$ and $X_{r s 8}$ with respect to baseline; and as change in Z-score (post-salbutamol Z-scorebaseline Z-score) for $\mathrm{R}_{\mathrm{rs} 8}$ and $\mathrm{X}_{\mathrm{rs} 8}$ calculated from the baseline data. SPSS for Windows (version 16.0) was used for the analysis. A two-tailed $P$-value of $<0.05$ was considered as statistically significant.

\section{RESULTS}

Questionnaires were distributed to families of 690 children and 324 were returned. Two children with neurological problems were excluded and consent for lung function testing was not obtained from 47 children. Eighty-four children had a diagnosis of asthma or had recurrent respiratory symptoms and were excluded from the current analysis. Measurements could not be attempted in 16 children due to equipment failure. Lung function measurements were attempted in 175 healthy children and data successfully obtained from 163 children aged 2.9-6.1 years. Demographic characteristics of the population are shown in Table 1. The success rate of FOT increased with age: being $66 \%(2 / 3)$ for children $<3$ years

TABLE 1-Characteristics of the Population of Children

\begin{tabular}{lc}
\hline & $\mathrm{n}=163$ \\
\hline Age, years & $4.8(2.9-6.1)$ \\
Male, $\mathrm{n}$ & $81(49.7)$ \\
Height, cm & $107.8(6.5)$ \\
Weight, kg & $19.9(3.5)$ \\
Personal history of atopy, $\mathrm{n}$ & $59(37.1)$ \\
Parental history of atopy, $\mathrm{n}$ & $37(24.7)$ \\
ETS exposure, $\mathrm{n}$ & $86(54.1)$ \\
\hline
\end{tabular}

Data are expressed as median (range) for age, mean (SD) for height and weight, and $\mathrm{n}(\%)$ for gender, personal history of atopy, parental history of atopy, and environmental tobacco smoke (ETS) exposure.
TABLE 2-Group MEAN and SD of $R_{r s}$ and $X_{r s}$ and the Within-Test Variability in the Study Population

\begin{tabular}{lcccc}
\hline & Mean & SD & CV $(\%)$ & $\mathrm{n}$ \\
\hline $\mathrm{R}_{\mathrm{rs} 6} \mathrm{hPa} \mathrm{s} \mathrm{L}^{-1}$ & 8.40 & 0.74 & 8.8 & 143 \\
$\mathrm{R}_{\mathrm{rs} 8} \mathrm{hPa} \mathrm{s} \mathrm{L}^{-1}$ & 8.49 & 0.49 & 5.9 & 163 \\
$\mathrm{R}_{\mathrm{rs} 10} \mathrm{hPa} \mathrm{s} \mathrm{L}^{-1}$ & 8.16 & 0.51 & 6.3 & 163 \\
$\mathrm{X}_{\mathrm{rs} 6} \mathrm{hPa} \mathrm{s} \mathrm{L}^{-1}$ & -3.24 & 0.55 & 17.2 & 143 \\
$\mathrm{X}_{\mathrm{rs} 8} \mathrm{hPa} \mathrm{s} \mathrm{L}^{-1}$ & -2.45 & 0.43 & 18.8 & 163 \\
$\mathrm{X}_{\mathrm{rs} 10} \mathrm{hPa} \mathrm{s}^{-1}$ & -2.23 & 0.38 & 18.6 & 163 \\
\hline
\end{tabular}

$\mathrm{SD}$, standard deviation; $\mathrm{CV}$, coefficient of variation.

old; $90.6 \%$ (29/32) for children from 3 to $<4$ years; $94.4 \%$ (67/71) for children from 4 to $<5$ years; $93.8 \%(61 / 65)$ for children aged 5 to $<6$ years, and $100 \%$ (4/4) for children older than 6 years of age.

Group mean data for $\mathrm{R}_{\mathrm{rs}}$ and $\mathrm{X}_{\mathrm{rs}}$ at 6,8 , and $10 \mathrm{~Hz}$ as well as the within-test variability are reported in Table 2 . A smaller number of acceptable measurements for $\mathrm{R}_{\mathrm{rs} 6}$ were obtained due to coherence $<0.95(n=143)$. There were no significant sex differences in any variable. The prediction equations for the relationship between height $(\mathrm{Ht})$ and respiratory impedance were determined and the standard deviation of residuals (RSD) calculated. The result for the frequencies of 6,8 , and $10 \mathrm{~Hz}$ is shown in Table 3 . Weight, age, personal and parental history of atopy, as well as ETS exposure did not significantly affect $\mathrm{Z}_{\mathrm{rs}}$ after taking height into account. The relationship between height and $\mathrm{R}_{\mathrm{rs}}$ and $\mathrm{X}_{\mathrm{rs}}$ at $8 \mathrm{~Hz}$ for study population is shown in Figure 1 .

Short-term repeatability of the test was assessed in 44 children. A smaller number of acceptable measurements for $R_{r s 6}$ were obtained due to coherence $<0.95(n=37)$. $\mathrm{CR}$ for $\mathrm{R}_{\mathrm{rs}}$ and $\mathrm{X}_{\mathrm{rs}}$ at 6,8 , and $10 \mathrm{~Hz}$ is shown in Table 4 . The difference between the two repeated measurements was not correlated to the mean values of the two measurements (data not shown).

BDR was assessed in 154 children. $\mathrm{R}_{\mathrm{rs} 8}$ and $\mathrm{X}_{\mathrm{rs} 8}$ changed significantly after salbutamol (baseline $\mathrm{R}_{\mathrm{rs} 8}$ $8.49 \mathrm{hPa} \mathrm{s} \mathrm{L}^{-1}$ versus post-salbutamol $\mathrm{R}_{\mathrm{rs} 8} 7.40 \mathrm{hPa} \mathrm{s} \mathrm{L}^{-1}$, $P<0.001$; baseline $X_{\mathrm{rs} 8}-2.44 \mathrm{hPasL}^{-1}$ versus postsalbutamol $\left.\mathrm{X}_{\mathrm{rs} 8}-1.73 \mathrm{hPasL}^{-1}, P<0.001\right)$. The 5th percentile for the absolute $\mathrm{R}_{\mathrm{rs} 8} \mathrm{BDR}$ was $-3.16 \mathrm{hPa} \mathrm{s} \mathrm{L}^{-1}$,

TABLE 3-Regression Relationship Between Respiratory Impedance and Height in the Study Population

\begin{tabular}{lcccc}
\hline & Equation & RSD & R-square & $P$-value \\
\hline $\mathrm{R}_{\text {rs6 }}$ & $23.452-(0.139 \times \mathrm{Ht})$ & 1.79 & 0.204 & $<0.001$ \\
$\mathrm{R}_{\mathrm{rs} 8}$ & $22.692-(0.132 \times \mathrm{Ht})$ & 1.70 & 0.202 & $<0.001$ \\
$\mathrm{R}_{\mathrm{rs} 10}$ & $21.453-(0.123 \times \mathrm{Ht})$ & 1.52 & 0.216 & $<0.001$ \\
$\mathrm{X}_{\mathrm{rs} 6}$ & $-11.990+(0.081 \times \mathrm{Ht})$ & 0.84 & 0.280 & $<0.001$ \\
$\mathrm{X}_{\mathrm{rs} 8}$ & $-9.584+(0.066 \times \mathrm{Ht})$ & 0.91 & 0.182 & $<0.001$ \\
$\mathrm{X}_{\mathrm{rs} 10}$ & $-9.001+(0.063 \times \mathrm{Ht})$ & 0.94 & 0.158 & $<0.001$ \\
\hline
\end{tabular}

$\mathrm{RSD}$, standard deviation of residuals; $\mathrm{Ht}$, height in centimetres. 


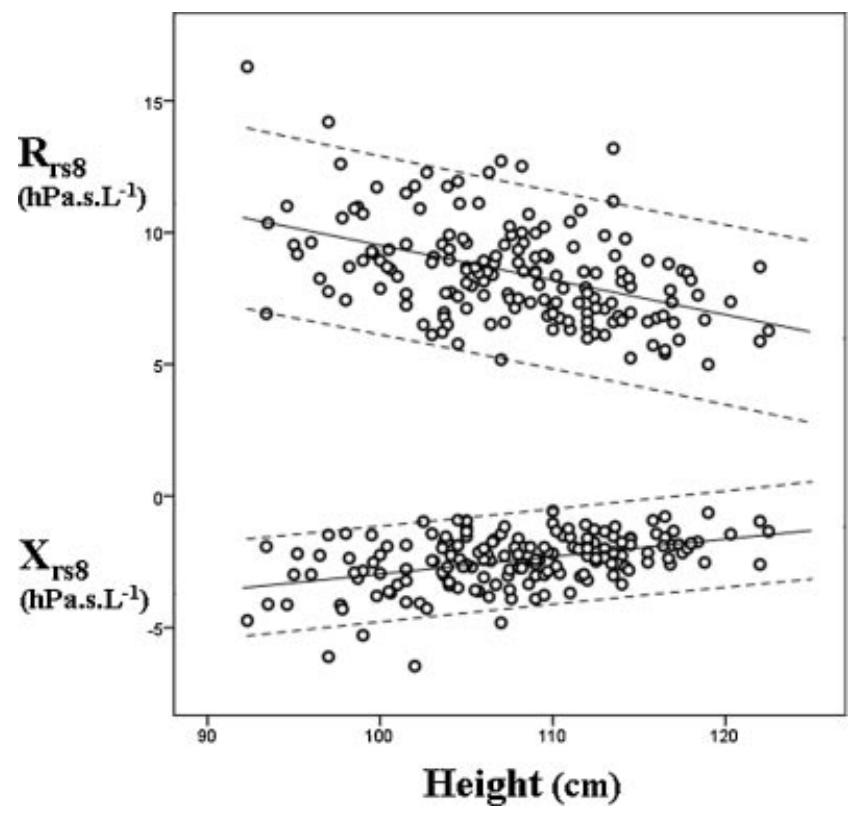

Fig. 1. Relationship between height and respiratory impedance $Z_{r s}$ at $8 \mathrm{~Hz}$ in preschool children. The single values are expressed as circles, the regression line and the $95 \%$ confidence intervals are shown as solid lines. Respiratory resistance at $8 \mathrm{~Hz}\left(\mathbf{R}_{\mathrm{rs} 8}\right)$. Respiratory reactance at $8 \mathrm{~Hz}\left(\mathrm{X}_{\mathrm{rs} 8}\right)$.

whereas the 95 th percentile for the absolute $\mathrm{X}_{\mathrm{rs} 8}$ BDR was $2.25 \mathrm{hPa} \mathrm{s} \mathrm{L}^{-1}$. These cut-off values corresponded to a percent change with respect to baseline of $-34 \%$ and $61 \%$, respectively, and a change in the $\mathrm{Z}$-score of -1.88 and 2.48 , respectively. The changes in all three indices of bronchodilation were related to the magnitude of the baseline measurement for both $\mathrm{R}_{\mathrm{rs} 8}$ and $\mathrm{X}_{\mathrm{rs} 8}$ (Table 5, Fig. 2). BDR, expressed as a percent of baseline, was correlated with height for $R_{r s 8}(r=0.18, b=-0.386$, $P=0.029)$, but not for $\mathrm{X}_{\mathrm{rs} 8} \quad(\mathrm{r}=0.13, \mathrm{~b}=0.712$, $P=0.112$ ). No significant correlations were found between height and absolute BDR $(\mathrm{r}=0.09, \mathrm{~b}=$ $-0.017, P=0.287$ for $\mathrm{R}_{\mathrm{rs} 8} ; \mathrm{r}=0.20, \mathrm{~b}=-0.002$, $P=0.805$ for $\left.\mathrm{X}_{\mathrm{rs} 8}\right)$ or change in Z-score $(\mathrm{r}=0.09$, $\mathrm{b}=-0,010, P=0.287$ for $\mathrm{R}_{\mathrm{rs} 8} ; \mathrm{r}=0.02, \mathrm{~b}=-0.003$, $P=0.805$ for $\mathrm{X}_{\mathrm{rs} 8}$ ).

Using the Australian equations ${ }^{18}$ to calculate Z-scores for Italian children and comparing then with Z-scores

TABLE 4-Mean Absolute and Relative Coefficient of Repeatability (CR) for $R_{\mathrm{rs}}$ and $\mathrm{X}_{\mathrm{rs}}$ at 6,8 , and $10 \mathrm{~Hz}$.

\begin{tabular}{lccc}
\hline & $\begin{array}{c}\text { Absolute CR } \\
\left(\mathrm{hPas} \mathrm{L}^{-1}\right)\end{array}$ & $\begin{array}{c}\text { Relative CR } \\
(\%)\end{array}$ & $\mathrm{n}$ \\
\hline $\mathrm{R}_{\mathrm{rs6}}$ & 2.18 & 26.90 & 37 \\
$\mathrm{R}_{\mathrm{rs} 8}$ & 1.53 & 18.78 & 44 \\
$\mathrm{R}_{\mathrm{rs} 10}$ & 1.29 & 16.45 & 44 \\
$\mathrm{X}_{\mathrm{rs6}}$ & 1.17 & 40.85 & 37 \\
$\mathrm{X}_{\mathrm{rs} 8}$ & 0.91 & 39.22 & 44 \\
$\mathrm{X}_{\mathrm{rs} 10}$ & 0.89 & 43.37 & 44 \\
\hline
\end{tabular}

TABLE 5-Different Indices of Bronchodilation for $\mathbf{R}_{\mathbf{r s}}$ and $X_{r s}$ at $8 \mathrm{~Hz}$ and Their Relationship With the Magnitude of the Baseline Measurement Expressed As r (Correlation Coefficient) and b (Regression Coefficient)

\begin{tabular}{lccc}
\hline & $\mathrm{r}$ & $\mathrm{b}$ & $P$ \\
\hline $\mathrm{R}_{\mathrm{rs} 8}$ absolute change & 0.49 & -0.317 & $<0.001$ \\
$\mathrm{X}_{\mathrm{rs8}}$ absolute change & 0.67 & -0.523 & $<0.001$ \\
$\mathrm{R}_{\mathrm{rs} 8}$ change in percent baseline & 0.30 & -2.249 & $<0.001$ \\
$\mathrm{X}_{\mathrm{rs} 8}$ change in percent baseline & 0.33 & -11.525 & $<0.001$ \\
$\mathrm{R}_{\mathrm{rs} 8}$ change in Z-score & 0.49 & -0.189 & $<0.001$ \\
$\mathrm{X}_{\mathrm{rs} 8}$ change in Z-score & 0.67 & -0.574 & $<0.001$ \\
\hline
\end{tabular}

calculated using the Italian equations from the present study showed minor differences for $\mathrm{R}_{\mathrm{rs} 10}(0.23$, $P=0.036), \mathrm{X}_{\mathrm{rs} 8}(0.32, P=0.012)$, and $\mathrm{X}_{\mathrm{rs} 10}(0.65$, $P<0.001)$. No significant differences were found for $\mathrm{R}_{\mathrm{rs} 6}(-0.02, P=0.82), \mathrm{R}_{\mathrm{rs} 8}(0.10, P=0.43)$, and $\mathrm{X}_{\mathrm{rs} 6}$ $(-0.02, P=0.68)$. The equations for $\mathrm{R}_{\mathrm{rs} 8}$ and $\mathrm{X}_{\mathrm{rs} 8}$ for both the Australian and the Italian populations are shown in Figure 3.

\section{DISCUSSION}

The results of the present study confirm that the FOT is feasible and is a potentially useful tool for evaluating lung function in preschool children. With this study, we provide reference data for Italian children. In addition, we have shown that the technique is repeatable and appropriate for assessing bronchodilation as change in $\mathrm{R}_{\mathrm{rs}}$ or $\mathrm{X}_{\mathrm{rs}} \mathrm{Z}$-score.

According to the most recent ATS/ERS recommendations ${ }^{1}$ the measurements should be considered acceptable primarily based on the coefficient of variability $(\mathrm{CV})$ of the individual frequencies. In the present study, measurements in which three or more individual frequencies had a coherence of $<0.95$ were excluded. Rejecting data at a single frequency where the coherence is $<0.95$ is important as this provides a recognized standard for quality control and is built into the software of the I2M FOT device. Data with lower coherence suggests low signal to noise ratio and a violation of the underlying assumption of a linear relationship between the input and output signals. We recommend reporting $\mathrm{R}_{\mathrm{rs}}$ and $\mathrm{X}_{\mathrm{rs}}$ at $8 \mathrm{~Hz}$ as these data can be obtained from most children and are reproducible in the short term (Table 2).

From a clinical point of view it is very important to have appropriate reference data for a given population. FOT can be used in young or older children not able to perform spirometry. Knowing the reference equation it is possible to detect abnormal lung function and, as previously mentioned, FOT can then be used in the follow-up of children with lung diseases such as asthma, neonatal chronic lung disease, or cystic fibrosis or asthma. ${ }^{5,7-9,13-14}$ The reference equations calculated from the healthy Italian children in the present study are very similar to those published by Hall et al. ${ }^{18}$ from Australian children 
who have used a different commercial implementation of the same basic equipment and methodology. Hall et al. ${ }^{18}$ have already compared the Australian $\mathrm{Z}_{\mathrm{rs}}$ equation to those published previously from other large populations of children measured with different equipment; showing that even when performed under different conditions, the different reference values were very similar. Using the Australian equations ${ }^{18}$ to calculate Z-scores for Italian children and comparing them with Z-scores calculated using the Italian equations from the present study, no
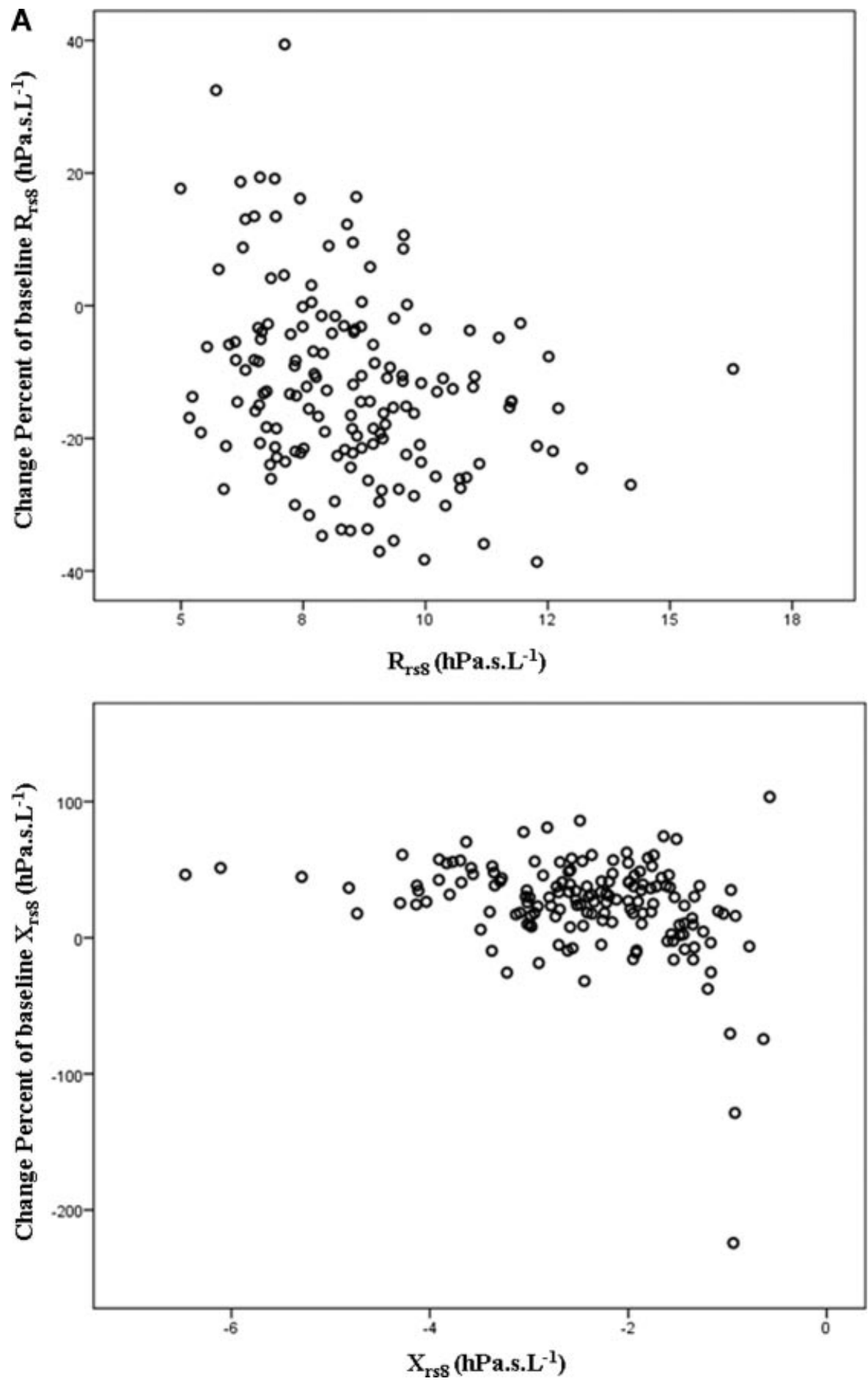

Fig. 2. Bronchodilator response as a function of baseline values expressed as (A) percent of baseline $R_{r s 8}$ and $X_{r s 8}$; $(B)$ absolute change in $R_{r s 8}$ and in $X_{r s 8}$; and $(C)$ change in $Z$-score for $\mathbf{R}_{\mathrm{rs8}}$ and $\mathbf{X}_{\mathrm{rs8}}$. 

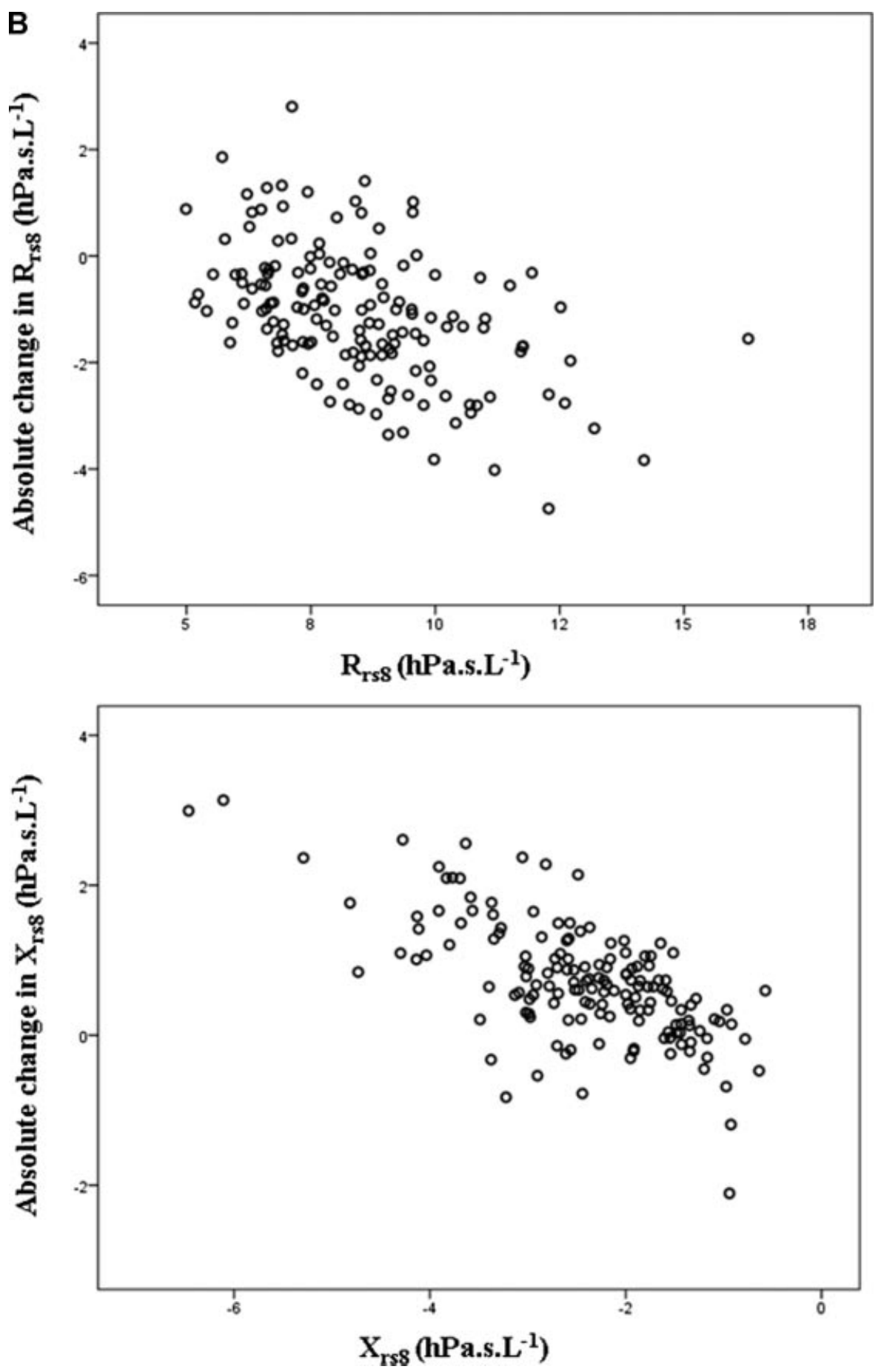

Fig. 2. (Continued)

significant difference for $\mathrm{R}_{\mathrm{rs} 8}$ and only a minor difference for $\mathrm{X}_{\mathrm{rs} 8}$ was found. Both study populations were largely Caucasian and of similar age and height range. The Italian data were collected in the field whereas the Australian data were largely collected in a specialized pulmonary function laboratory. The similarity in the equations, as shown in Figure 3, encourages an effort to combine data sets from different parts of the world to provide an international reference data set, as has been done for other techniques. Such a data set would also allow appropriate examination of potential influences on lung function, such as sex, atopy, family history of asthma, and atopy that are rarely significant in individual data sets due to limited sample size.

For the clinical interpretation of the measurements it is necessary to consider the repeatability of the test. In the 

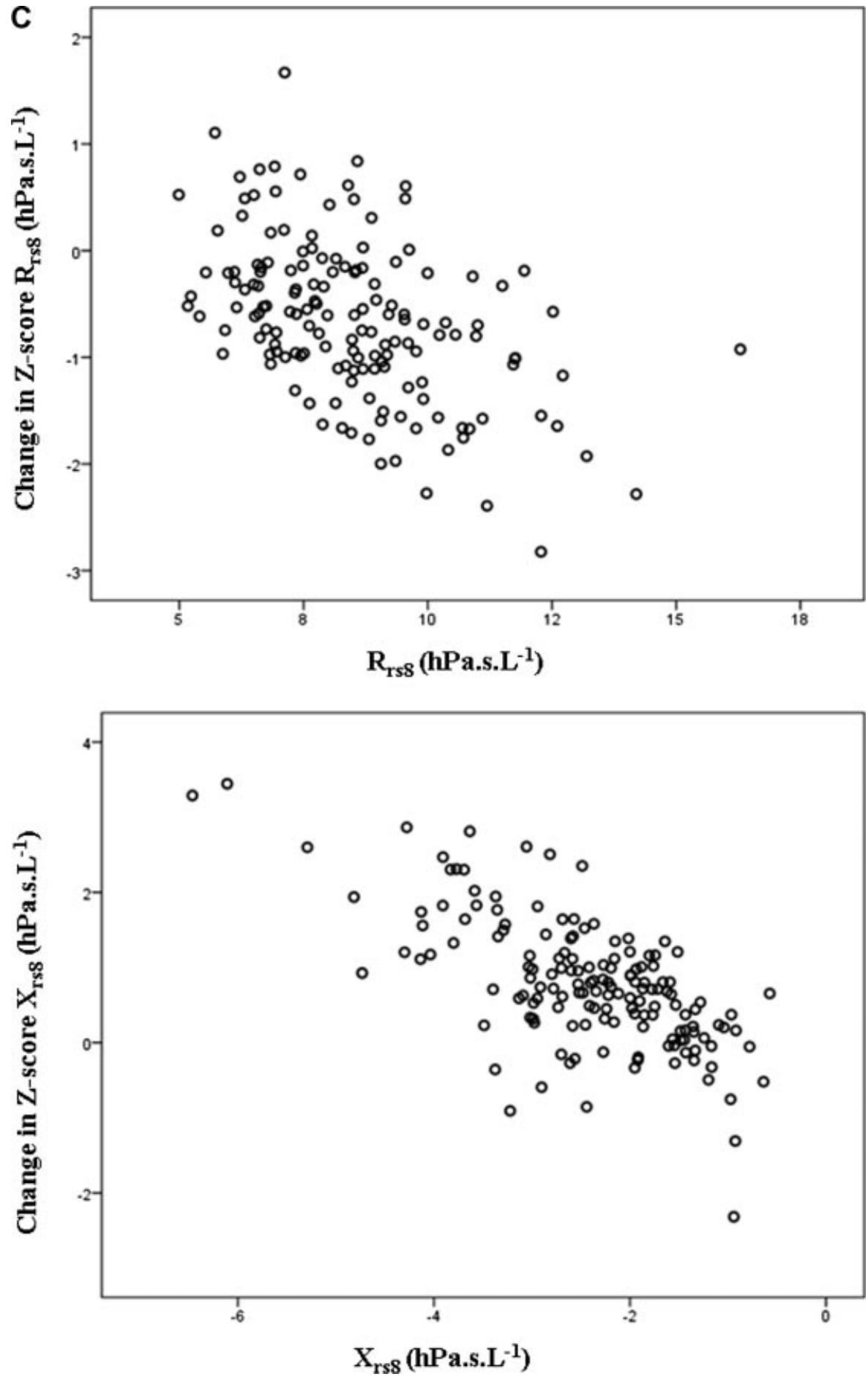

Fig. 2. (Continued)

current study, between-measurement repeatability was defined as absolute CR $(2 \times \mathrm{SD}$ of the difference between the repeated measurements made 15 min apart), according to the international recommendations, ${ }^{1}$ and relative $\mathrm{CR}$ $(2 \times \mathrm{SD}$ of the difference between repeated measurements as a percentage of the mean of the two measurements). We have reported an absolute and a relative CR for $R_{r s 8}$ and for $\mathrm{X}_{\mathrm{rs} 8}$ (as shown in Table 4) that are similar to other previously published between-measurement repeatability values. ${ }^{18-20}$ This short-term CR describes the variability introduced by having the child make two sets of measurements $15 \mathrm{~min}$ apart. Sources of variability that may contribute to this $\mathrm{CR}$ include: different breathing pattern; different level of engagement and co-operation by 


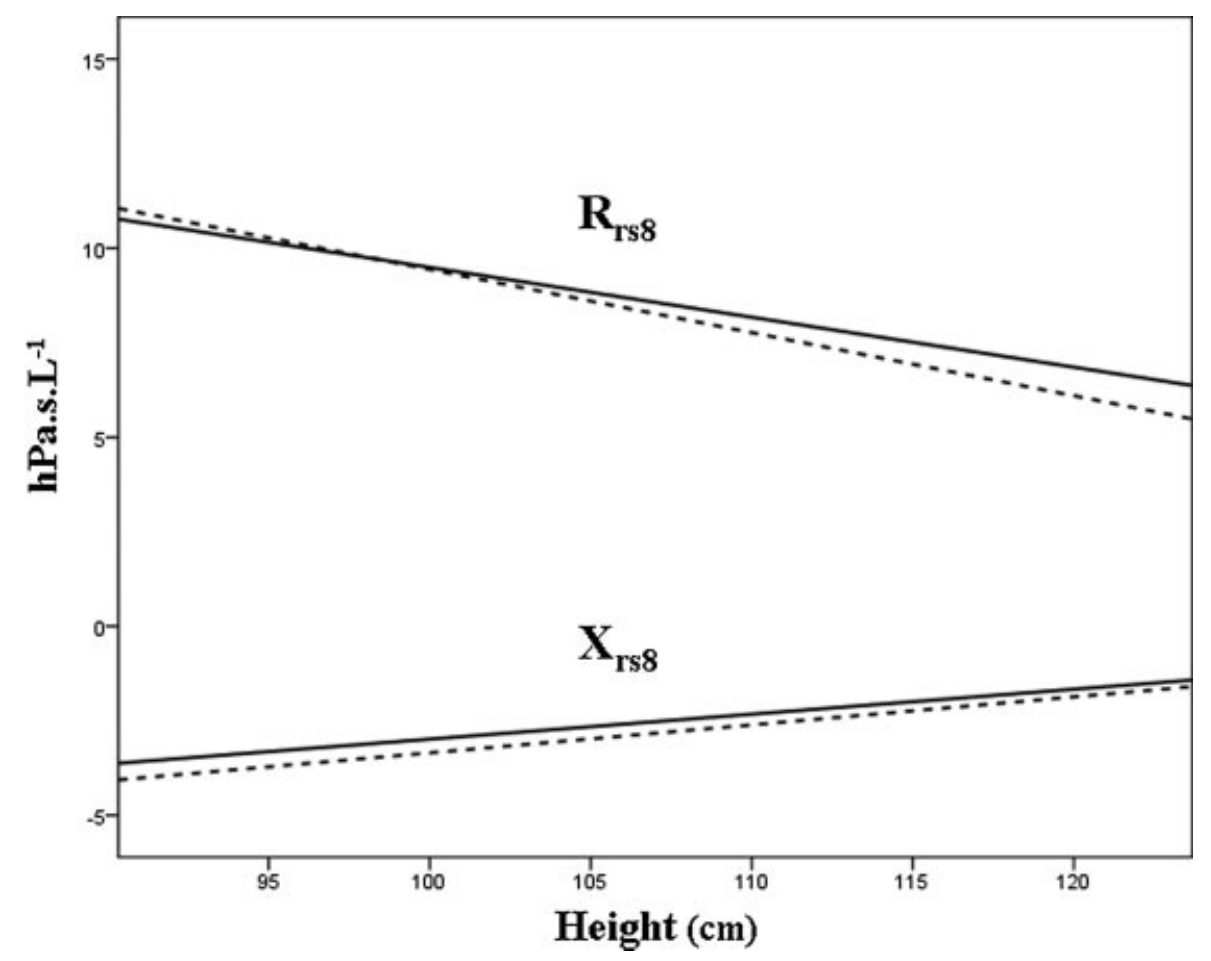

Fig. 3. Predicted values for respiratory resistance $\left(R_{r s 8}\right)$ and reactance $\left(X_{r s 8}\right)$ at $8 \mathrm{~Hz}$ using the equations by Hall et al. ${ }^{18}$ (dashed lines) and the equations reported in the present study (full lines).

the child; and any minute to minute fluctuations in airway calibre due to changes in airway tone. It is reasonable to expect that true changes in the physiological state of the lungs will be minimal in healthy children over this time interval. Knowledge of these short-term changes in measured lung function without any therapeutic intervention are vital to interpreting true changes due to salbutamol inhalation. However, in the present study, we have found that the change in lung function in healthy preschool children after salbutamol was higher than the short-term variability of the test, reflecting a true BDR and highlighting the importance of cut-off for BDR based on measurements in healthy preschoolers.

In the present study, we assessed BDR using $\mathrm{R}_{\mathrm{rs}}$ and $\mathrm{X}_{\mathrm{rs}}$ at $8 \mathrm{~Hz}$ as these were previously recommended by Thamrin et al. ${ }^{10}$ Our data onfirm their earlier data that the change in both $\mathrm{R}_{\mathrm{rs}}$ and $\mathrm{X}_{\mathrm{rs}}$ following bronchodilator was related to the magnitude of the baseline values. In our study, we have found a correlation between BDR expressed as a percent of baseline and height for $R_{\mathrm{rs} 8}$. $\mathrm{BDR}$, as measured by FOT, is an expression of the change in airway caliber following inhalation of a bronchodilator. The change in $R_{r s}$ is directly related to the increase in airway caliber of conducting airways, that is, those airways in which gas movement occurs by bulk flow. Although, $X_{\mathrm{rs}}$ primarily reflects the elastic and inertive properties of the respiratory system, the mechanical properties of small airways, that is those in which gas movement occurs by facilitated diffusion, are also included. Thus, the change in $\mathrm{X}_{\mathrm{rs}}$ with bronchodilator is more complex. The airways become larger and the respiratory system becomes less stiff with growth and development, reflected here by both baseline lung function and height. Thus, it is not surprising that we found a relationship between the magnitude of the BDR and both baseline lung function and height. Oostveen et al. ${ }^{14}$ have recently argued that using absolute change in lung function to express BDR avoids hiding differences in baseline bronchomotor tone, which they implied underlies the difference in baseline lung function in children with different wheeze phenotypes. However, as argued by Thamrin et al. ${ }^{22}$ correcting for differences in airway caliber due to size rather than underlying bronchomotor tone is critical to getting the clinical interpretation correct. Normalizing lung function to the child's height, as occurs by using Z-score or expressing lung function as a percent of the predicted value, should remove height-dependence of the BDR. Indeed, in the present study by using Z-scores to represent $R_{\mathrm{rs} 8}$ and $\mathrm{X}_{\mathrm{rs} 8}$ the change in lung function following bronchodilator was no longer related to the child's height. This finding is similar to that reported by the Australian group. ${ }^{18}$

The major difference between our study and the one from Thamrin et al. ${ }^{10}$ is the use of $600 \mu \mathrm{g}$ of salbutamol to assess BDR whereas $200 \mu \mathrm{g}$ was used in the present study. Despite this difference, the change in both $R_{r s 8}$ and $X_{r s 8}$ 
with salbutamol was similar, being $40 \%$ and $35 \%$, respectively, for $\mathrm{R}_{\mathrm{rs} 8}$ and $65 \%$ and $61 \%$, respectively, for $\mathrm{X}_{\mathrm{rs} 8}$. The similarities in BDR despite the substantial difference in salbutamol dose show that $200 \mu \mathrm{g}$ is sufficient for healthy children and likely reflects a relatively flat dose-response curve in such children. Other studies have reported similar changes in lung function following bronchodilatation measured with FOT in asthmatic children ${ }^{13}$ or with different wheezing phenotypes. $^{14}$

In conclusion, the data from the present study give the reference equation for $\mathrm{R}_{\mathrm{rs}}$ and $\mathrm{X}_{\mathrm{rs}}$ for Italian children between 2 and 6 years of age. The data also demonstrate that healthy Italian preschool children have similar lung function, as assessed by the FOT using the similar commercially available equipment, to healthy Australian preschool children. In addition, we have demonstrated that the most appropriate index for determine BDR is a decrease in $R_{\mathrm{rs} 8} Z$-score of $\geq 1.88$ or an increase in $X_{\mathrm{rs} 8}$ $\mathrm{Z}$-score of $\geq 2.48$ in preschool children.

\section{ACKNOWLEDGMENTS}

We would like to thank all children, families and school teachers participating in the study. We also would like to acknowledge for their funding and support. "Associazione Solidarietà e Servizio" NGO, Viterbo, Italy; Cassa di Risparmio di Viterbo, Italy.

\section{REFERENCES}

1. Beydon N, Davis SD, Lombardi E, Allen JL, Arets HG, Aurora P, Bisgaard H, Davis GM, Ducharme FM, Eigen H, Gappa M, Gaultier C, Gustafsson PM, Hall GL, Hantos Z, Healy MJ, Jones MH, Klug B, Lodrup Carlsen KC, McZenzie SA, Marchal F, Mayer OH, Merkus PJ, Morris MG, Oostveen E, Pillow JJ, Seddon PC, Silverman M, Sly PD, Stocks J, Tepper RS, Vilozni D, Wilson NM, American Thoracic Society/European Respiratory Society Working Group on Infant and Young Children Pulmonary Function Testing. An Official American Thoracic Society/European Respiratory Society Statement: pulmonary function testing in preschool children. Am J Respir Crit Care Med 2007; 175:1304-1345.

2. Duiverman EJ, Clément J, van de Woestijne KP, Neijens HJ, van de Bergh AC, Kerrebijn KF. Forced oscillation technique. Reference values for resistance and reactance over a frequency spectrum of $2-26 \mathrm{~Hz}$ in healthy children aged $2.3-12.5$ years. Bull Eur Physiopathol Respir 1985;21:171-178.

3. Lebecque P, Desmond K, Swartebroeckx Y, Dubois P, Lulling J, Coates A. Measurement of respiratory system resistance by forced oscillation in normal children: a comparison with spirometric values. Pediatr Pulmonol 1991;10:117-122.

4. Lall CA, Cheng N, Hernandez P, Pianosi PT, Dali Z, Abouzied A, Maksym GN. Airway resistance variability and response to bronchodilator in children with asthma. Eur Respir J 2007;30: 260-268.

5. Gangell CL, Horak F, Jr., Patterson HJ, Sly PD, Stick SM, Hall GL. Respiratory impedance in children with cystic fibrosis using forced oscillations in clinic. Eur Respir J 2007;30:892-897.
6. Ren CL, Brucker JL, Rovitelli AK, Bourdeaux KA. Changes in lung function measured by spirometry and the forced oscillation technique in cystic fibrosis patients undergoing treatment for respiratory tract exacerbation. Pediatr Pulmonol 2006;41:345349.

7. Malmberg LP, Mieskonen S, Pelkonen A, Kari A, Sovijarvi ARA, Turpeinen M. Lung function measured by the oscillometric method in prematurely born children with chronic lung disease. Eur Respir J 2000;16:598-603.

8. Vrijlandt EJ, Boezen HM, Gerritsen J, Stremmelaar EF, Duiverman EJ. Respiratory health in prematurely born preschool children with and without bronchopulmonary dysplasia. J Pediatr 2007; 150:256-261.

9. Udomittipong K, Sly PD, Patterson HJ, Gangell CL, Stick SM, Hall GL. Forced oscillations in the clinical setting in young children with neonatal lung disease. Eur Respir J 2008;31:12921299.

10. Thamrin C, Gangell CL, Udomittipong K, Kusel MMH, Patterson H, Fukushima T, Schultz A, Hall GL, Stick SM, Sly PD. Assessment of bronchodilator responsiveness in preschool children using forced oscillations. Thorax 2007;62:814-819.

11. Delacourt C, Lorino H, Herve-Guillot M, Reinert P, Harf A, Housset B. Use of the forced oscillation technique to assess airway obstruction and reversibility in children. Am J Respir Crit Care Med 2000;161:730-736.

12. Delacorurt C, Lorino H, Fuhrman C, Herve-Guilliot M, Reinert $P$, Harf A, Housset B. Comparison of the forced oscillation technique and the interrupter technique for assessing airway obstruction and its reversibility in children. Am J Respir Crit Care Med 2001;164:965-972.

13. Vu LTT, Demoulin B, Nguyen MTH, Nguten YT, Marchal F. Respiratory impedance and response to salbutamol in asthmatic Vietnamese children. Pediatr Pulmonol 2010;45:380-386.

14. Oostveen E, Dom S, Desager K, Hagendorens M, De backer W, Weyler J. Lung function and bronchodilator response in 4-yearold children with different wheezing phenotypes. Eur Resp J 2010;35:865-872.

15. Ducharme FM, Davis GM, Ducharme GR. Pediatric reference values for respiratory resistance measured by forced oscillation. Chest 1998;113:1322-1328.

16. Hordvik NL, König P, Morris DA, Kreutz C, Pimmel RL. Normal values for forced oscillatory respiratory resistance in children. Pediatr Pumonol 1985;1:145-148.

17. Solymar L, Aronsson PH, Bake B, Bjure J. Respiratory resistance and impedance magnitude in healthy children aged $2-18$ years. Pediatr Pulmonol 1985;1:134-140.

18. Hall GL, Sly PD, Fukushima T, Kusel MM, Franklin PJ, Horak F, Jr., Patterson H, Gangell C, Stick SM. Respiratory function in healthy young children using forced oscillations. Thorax 2007;62: $521-526$.

19. Malmberg LP, Pelkonen A, Poussa T, Pohjanpalo Haahtela T, Turpeinem M. Determinants of respiratory system input impedance and bronchodilator response in healthy Finnish preschool children. Clin Physiol Funct Imaging 2002;22:64-71.

20. Klug B, Bisgaard H. Specific airway resistance, interrupter resistance, and respiratory impedance in healthy children aged 27 years. Pediatr Pulmonol 1998;25:322-331.

21. Asher MI, Keil U, Anderson HR, Beasley R, Crane J, Martinez F, Mitchell EA, Pearce N, Sibbald B, Stewart AW, Strachan D, Weiland SK, Williams HC. International study of asthma and allergies in childhood (ISAAC): rationale and methods. Eur Resp J 1995;8:483-491.

22. Thamrin C, Gangell CL, Kusel MMH, Schultz A, Hall GL, Stick SM, Sly PD. Expression of bronchodilator response using FOT measurements: absolute versus relative. Eur Respir J (letter) 2010; in press. 